\title{
Director for the College Research Unit
}

The President is pleased to announce the appointment of Dr Paul Lelliott as Director of the College Research Unit, with effect from 1 October
1994, following the retirement of the present Director, Professor John Wing. Dr Lelliott is presently the Deputy Director of the Unit.

\section{The Mental Health Review Tribunal Service: Applications for medical membership}

The Mental Health Review Tribunal service is keen to increase the number of medical members, especially in and around London, and would welcome applications from psychiatrists interested in this area of work. Mental Health Review Tribunals have statutory responsibility for reviewing the cases of patients who have been compulsorily detained under the Mental Health Act 1983. Detained patients can seek a review of their case by applying to a Tribunal. Each Tribunal is made up of three part-time members, lay, medical and legal; the legal member acts as the chairman. Tribunals must consider whether it is necessary for the patient to continue to be compulsorily detained in hospital or whether other arrangements for care and treatment would be more appropriate.
Tribunals take place at the hospital where the patient is detained. Members must therefore be prepared to travel to these hospitals some of which are in remote locations. They will usually be expected to sit on at least two Tribunals at the hospital on the day. Each member is likely to sit no more than $\mathbf{5 0}$ days in a year.

Medical members receive a daily fee (under review) of $£ 217.40$ plus expenses. The medical member is required to examine the patient before the hearing to form an opinion about the patient's mental state. This is usually carried out a day or so beforehand, for which a fee and expenses are also payable.

If you would like further details please contact Mrs Vanessa Cameron, College Secretary, for a background note and application form.

\section{The Library and Information Service}

During the summer period the College Library will remain open, apart from the two weeks around the Bank Holiday - from 22 August to 2 September 1994.

\section{Focus on mental health}

Among the events planned for World Mental Health Day, 10 October 1994, are: 'From Controversies to Consensus', the launch of the College's community care policy, to be held at the QEII Conference Centre, London; and 'Light a Spark for Mental Health' - groups around the country are invited to light a sparkler and help raise the profile of mental health. Further information: Deborah Hart at the College. 